\title{
Meta-Analysis of the Effect of the Clinical Pathway Applied to Patients with Endoscopic Sinus Surgery in China
}

\author{
Bai Yong-Mei ${ }^{a} \quad$ Han De-Min ${ }^{b}$ Wang Dong-Bo ${ }^{b} \quad$ Ma Qi-Zhic \\ Pan Yue-Da ${ }^{a}$ \\ ${ }^{a}$ School of Public Health, Capital Medical University, Beijing, China; ${ }^{b}$ Beijing Tongren \\ Hospital, Capital Medical University, Beijing, China; ${ }^{\circ}$ Department of Thoracic Oncology, \\ West China Hospital, Sichuan University, Chengdu, China
}

\section{Keywords}

Chronic rhinosinusitis - Endoscopic sinus surgery · Clinical pathway · Meta-analysis

\begin{abstract}
Background: Chronic rhinosinusitis (CRS) is one of the most common diseases in China. The incidence of CRS in the Chinese urban population is between 5 and $15 \%$. It is difficult to cure with traditional surgery. Endoscopic sinus surgery is the first choice for the treatment of CRS. Compared with developed countries, the development of the clinical pathway of endoscopic sinus surgery in China is still unclear. Objectives: The aim is to explore whether the clinical pathway of endonasal sinus surgery is better than the traditional one in the Chinese population. Methods: We searched PubMed, Embase, the Cochrane Library, Web of Science, ClinicalTrials.gov, SinoMed, China National Knowledge Internet, Wanfang database of Chinese Journals, and VIP database of Chinese Journals. The last retrieval date was August 24, 2018. Review Manager 5.3 software was used for comprehensive quantification data analysis. $\boldsymbol{R e}$ sults: Fourteen papers involving 1,882 patients were included in this study. The results showed that compared with the traditional pathway, the clinical pathway can effectively shorten the average number of hospitalization days (mean difference, $\mathrm{MD}=-2.00,95 \% \mathrm{Cl}$ : $-2.50,-1.49$ ). In total, 10 of the 14 papers, with a total of 1,500 patients, proved that the clinical pathway can effectively reduce the hospitalization costs of patients (standard mean difference, SMD = $-3.15,95 \% \mathrm{Cl}:-4.20,-2.10) ; 11$ of the 14 papers, with a total of 1,488 patients, proved that the clinical pathway can effectively improve patients' knowledge of health $(95 \% \mathrm{Cl}: 1.03,1.09)$; and 7 of the 14 papers, with a total of 810 patients, proved that the clinical pathway can effectively improve patient satisfaction $(95 \% \mathrm{Cl}: 1.10,1.20)$. Conclusions: Our systematic review and meta-analysis support the use of the clinical pathway in patients with endoscopic sinus surgery in China.


Yong-Mei et al.: Clinical Pathway: Meta-Analysis

\section{Introduction}

Chronic rhinosinusitis (CRS) is a common disease in the field of rhinology and one of the most common diseases in China. CRS is defined by the European position paper on rhinosinusitis and nasal polyps (EPOS 2012) as "inflammation of the nose and the paranasal sinuses characterized by two or more symptoms, one of which should be either nasal blockage/ obstruction/congestion or nasal discharge(anterior/posterior nasal drip), facial pain/ pressure, reduction or loss of smell; and either endoscopic signs of polyps and/or mucopurulent discharge showing mucosal changes within the osteomeatal complex and/or sinuses". Chronic CRS can be acute when symptoms or signs persist for more than 12 weeks [1]. The incidence of CRS in the urban population of China is $5-15 \%$. The concordance of allergy and CRS ranges from 25 to $50 \%$, with pediatric studies reporting the higher association. In the subpopulation of patients with CRS symptomatic enough to require surgery, allergy is present in $41-84 \%$ of patients, with perennial hypersensitivity predominating [2]. It is difficult to cure with traditional surgery. Endoscopic sinus surgery is the first choice for the treatment of CRS at present [3]. China has introduced this technology since the 1990s; compared with the USA, Britain, Japan, and other countries, the development of the clinical pathway of endoscopic sinus surgery in China is still unclear [4].

Clinical pathway refers to a care plan with strict working order and exact time requirement made by a group of staff in a hospital for monitoring, treatment, rehabilitation and nursing of a certain disease, in order to reduce the delay of rehabilitation and waste of resources, and to enable the clients to obtain the best medical and nursing services. The clinical pathway can standardize the process of diagnosis and treatment, reduce the average number of hospitalization days and the hospitalization costs of patients, and help patients understand treatment plans, increase their knowledge of health, scientifically manage their own diseases, and improve preparedness.

There is growing recognition that the ultimate success of China's ambitious health reform (enacted in 2009) and higher education reform (1998) depends on well-educated health professionals who have the clinical, ethical, and human competencies necessary for the provision of quality services. The current standardized residency training (SRT) modernization might be viewed as a fundamental reform to restore public trust in the medical profession and achieve greater patient satisfaction. Even though the SRT has become a national strategy backed by substantial public financing, it also needs the necessary professional leadership and quality control (guaranteed by rigorous accreditation, certification, and faculty development) [5]. For residents, the clinical pathway can be used as a teaching guide for clinical training to grasp the diagnosis and treatment process and norms faster. SRT based on the clinical pathway can greatly shorten the time for diagnosis and treatment of common diseases or multiple diseases, and realize the promotion of high-quality medical technology to remote areas.

Since the implementation of the endoscopic sinus surgery clinical pathway in China, there has been no systematic evaluation of its implementation effect. Therefore, the purpose of our study is to systematically review the existing evidence on the effect of the endoscopic sinus surgery clinical pathway on patients' treatment effect, and determine whether the clinical pathway will affect the average number of hospitalization days, the hospitalization costs of patients, patients' knowledge of health, and patient satisfaction, and whether it will fill the gaps in related fields and provide data to support the necessity of promoting the clinical pathway of endoscopic sinus surgery. 
Table 1. Search terms for this study

Groups of search English search terms

terms

1

clinical pathway, critical pathway, care path, care map, care protocol, care process, integrated care pathway, cholecystectomy, advance care planning, advance directives, case management

2

chronic rhinosinusitis, chronic sinusitis, chronic nasosinusitis, chronic rhinosinusitis with nasal polyps, ethmoid sinusitis, frontal sinusitis, maxillary sinusitis, sphenoid sinusitis

Search terms in this table are based on the MeSH database of PubMed and Emtree of the Embase database.

\section{Materials and Methods}

\section{Data Sources and Literature Search}

Referring to the Cochrane intervention system evaluation manual, this study formulated retrieval strategies and recorded and reported the retrieval process [6]. The last retrieval date was August 24, 2018. We checked PubMed, Embase, Cochrane Library, Web of Science, ClinicalTrials.gov, SinoMed, China National Knowledge Internet, Wanfang database of Chinese Journals, and VIP database of Chinese Journal. We divided the search terms into two groups - chronic sinusitis and clinical pathway. We expanded the search terms based on the MeSH database of PubMed, Emtree of the Embase database, and existing meta-analysis (Table 1). The two groups of search terms were combined using "AND" to generate a subset of citations relevant to our search question. The reference lists of all known primary and review articles were hand searched to identify cited articles not captured by electronic searches.

\section{Selection of Studies}

Literature retrieval is carried out in databases and clinical trial registration platforms. Because the clinical pathway originated in the 1980s, we checked all database since the 1980s [7].

Firstly, the retrieved documents are categorized and sorted out in Endnote X7 to exclude duplicated documents. Secondly, the nonconforming documents are excluded through title and abstract reading, and further screened by reading the original text. Finally, the reasons for excluding documents are recorded in detail according to the inclusion and exclusion criteria.

\section{Inclusion Criteria}

(1) Type of study: a randomized controlled trial (RCT) of CRS treated by clinical pathway is included in all the studies mentioned in the literature, whether or not specific randomized methods are reported. (2) Objectives: the first diagnosis of chronic sinusitis in Chinese patients, regardless of gender, age, etc. (3) Interventions: the experimental group was treated by clinical pathway, while the control group was treated by traditional pathway. (4) Result-measuring indicators: the average number of hospitalization days, the hospitalization costs of patients, patients' knowledge of health, and patient satisfaction.

\section{Exclusion Criteria}

(1) Patients did not meet the diagnostic criteria for CRS or were not related to clinical pathways. (2) The outcome indicators are not represented by $(x \pm s)$ or the original data are missing, or the original literature cannot be found. (3) Patients with severe other diseases need to be transferred to other departments for treatment. (4) Only the clinical pathway is elaborated, but not implemented. (5) Case report, review, etc. (6) The dissertations and journal papers published by the same researchers using the same data are only included in journal papers. (7) Systematic review or meta-analysis.

\section{Assessment of Risk of Bias in Included Studies}

Data Extraction and Management

In order to ensure the correctness of data extraction, two evaluators conducted the literature screening and sorted out the basic information (author's name, publication time, research object, intervention measures, 


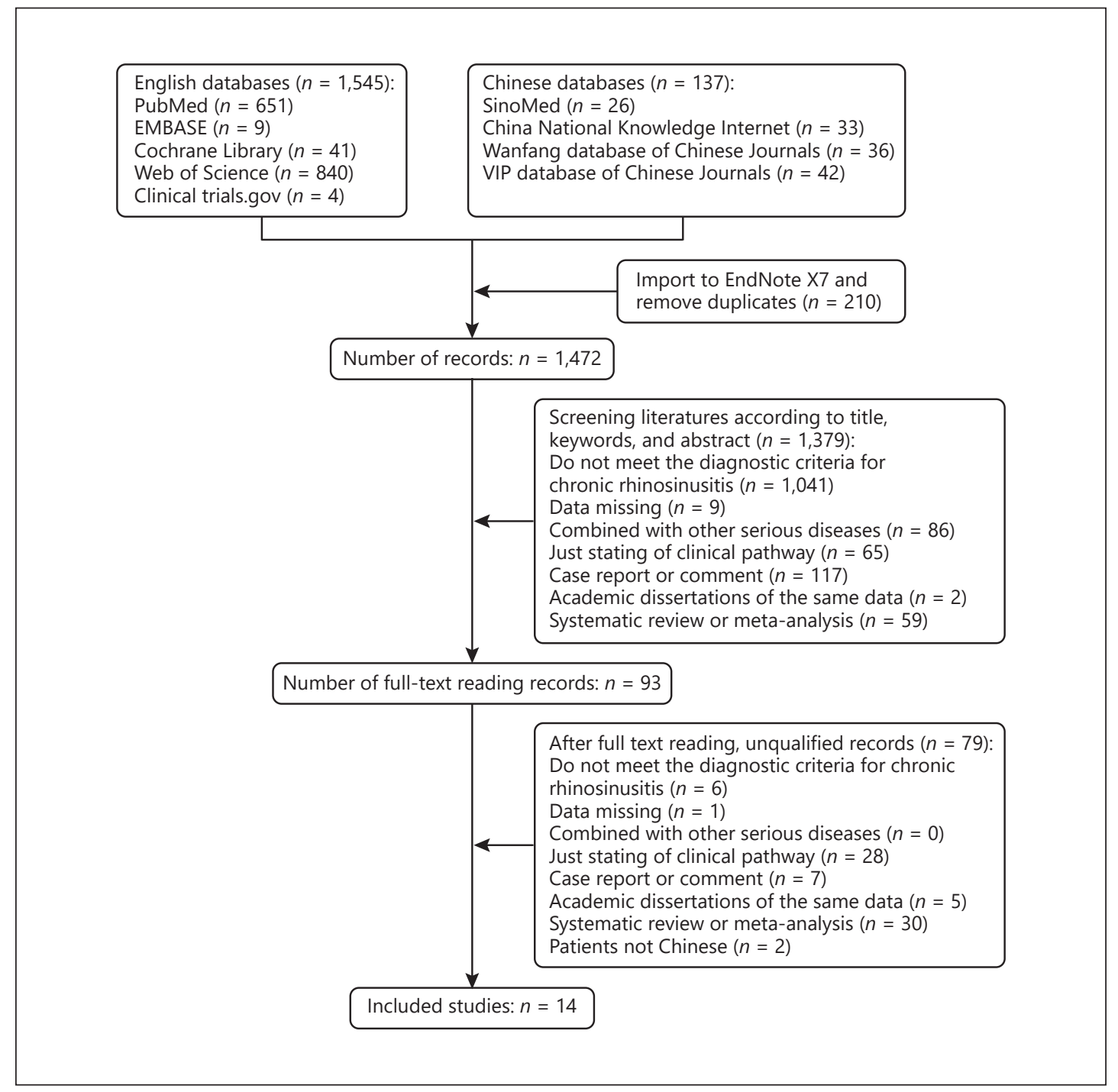

Fig. 1. Flowchart of the evaluated articles.

outcome indicators, and condition of follow-up) of the references included, at the same time collecting the information needed by the research, including the grouping of the research objects, the sample size of each group, the data of the outcome indicators, and so on. Statistical analysis was carried out after accurate and unified opinions. In case of disagreement, third-party experts were invited to make judgments. For missing data in references or research reports, contact the lead author by telephone or e-mail to supplement.

\section{Data Synthesis}

We used the Cochrane "Risk of bias" tool in RevMen5.3 [8] to evaluate the references or reports included in the study. Assessment was mainly carried out in six projects: sequence generation, allocation concealment, blinding, incomplete outcome data, selective outcome reporting, and other issue. Each index was judged as "low risk of bias," "high risk of bias" or "unclear risk of bias."

\section{Statistical Analysis}

RevMan 5.3 statistical software was used for data analysis. Heterogeneity between the results of each study was tested by $\chi^{2}$ test, and then the applied model was determined. There is no heterogeneity among the studies when $I^{2}=0$. The greater the numerical value, the greater the possibility of heterogeneity. There is a slight heterogeneity when $I^{2}=25 \%$, moderate heterogeneity when $I^{2}=50 \%$, and a high degree of hetero- 
Yong-Mei et al.: Clinical Pathway: Meta-Analysis

Table 2. Characteristics of the included studies (ordered by Ref. No.)

\begin{tabular}{|c|c|c|c|c|c|}
\hline $\begin{array}{l}\text { First author } \\
\text { [Ref.], year }\end{array}$ & Methods & Subjects & Interventions & Outcomes & $\begin{array}{l}\text { Follow- } \\
\text { up }\end{array}$ \\
\hline $\begin{array}{l}\text { Feng } \\
{[11], 2012}\end{array}$ & Random process & $\begin{array}{l}\text { Inpatients treated with } \\
\text { endoscopic surgery }\end{array}$ & $\begin{array}{l}\text { Under the } \\
\text { guidance of } \\
\text { clinical pathway }\end{array}$ & $\begin{array}{l}\text { Length of stay, patients' knowledge } \\
\text { of health, patient satisfaction, } \\
\text { postoperative complication rate }\end{array}$ & Yes \\
\hline $\begin{array}{l}\text { Huang } \\
{[12], 2010}\end{array}$ & $\begin{array}{l}\text { Multi-stage } \\
\text { convenient } \\
\text { sampling }\end{array}$ & $\begin{array}{l}\text { Patients treated with } \\
\text { endoscopic surgery, without } \\
\text { serious complications and } \\
\text { whose cardiac and renal } \\
\text { function is normal }\end{array}$ & $\begin{array}{l}\text { Clinical } \\
\text { pathway }\end{array}$ & $\begin{array}{l}\text { Length of stay, total hospitalization } \\
\text { expenses, treatment charge, } \\
\text { operation charge, examination } \\
\text { charge }\end{array}$ & - \\
\hline $\begin{array}{l}\text { Huang } \\
{[13], 2013}\end{array}$ & $\begin{array}{l}\text { Random process } \\
\text { after assessment }\end{array}$ & $\begin{array}{l}\text { Inpatients treated with } \\
\text { endoscopic surgery }\end{array}$ & $\begin{array}{l}\text { Clinical } \\
\text { pathway }\end{array}$ & $\begin{array}{l}\text { Length of stay, patient satisfaction, } \\
\text { awareness of health knowledge, } \\
\text { patients' compliance }\end{array}$ & - \\
\hline $\begin{array}{l}\mathrm{Li} \\
{[14], 2017}\end{array}$ & $\begin{array}{l}\text { Random number } \\
\text { table }\end{array}$ & $\begin{array}{l}\text { Chronic sinusitis treated with } \\
\text { endoscopic surgery }\end{array}$ & $\begin{array}{l}\text { Under the } \\
\text { guidance of } \\
\text { clinical pathway }\end{array}$ & $\begin{array}{l}\text { Length of stay, total hospitalization } \\
\text { expenses, patients' knowledge of } \\
\text { health, patient satisfaction, } \\
\text { complication, epistaxis, congestion } \\
\text { of nasal mucosa, hemorrhagic shock }\end{array}$ & Yes \\
\hline $\begin{array}{l}\text { Liu } \\
\text { [15], } 2009\end{array}$ & $\begin{array}{l}\text { Multi-stage } \\
\text { convenient } \\
\text { sampling }\end{array}$ & $\begin{array}{l}\text { Patients whose first diagnosis } \\
\text { was chronic sinusitis and who } \\
\text { were treated with endoscopic } \\
\text { surgery }\end{array}$ & $\begin{array}{l}\text { Clinical } \\
\text { pathway }\end{array}$ & $\begin{array}{l}\text { Length of stay, total hospitalization } \\
\text { expenses, patients' knowledge of } \\
\text { health, patient satisfaction, bed } \\
\text { charge, operation charge, anes- } \\
\text { thesia charge, examination charge, } \\
\text { medicine charge, percentage of } \\
\text { drug, other charges, operation } \\
\text { time, blood loss, variance }\end{array}$ & Yes \\
\hline $\begin{array}{l}\text { Liu } \\
{[16], 2015}\end{array}$ & Random selection & $\begin{array}{l}\text { Patients whose first diagnosis } \\
\text { was chronic sinusitis without } \\
\text { other serious complications }\end{array}$ & $\begin{array}{l}\text { Clinical nursing } \\
\text { pathway }\end{array}$ & $\begin{array}{l}\text { Length of stay, total hospitalization } \\
\text { expenses, patient satisfaction }\end{array}$ & - \\
\hline $\begin{array}{l}\text { Mao } \\
{[17], 2011}\end{array}$ & $\begin{array}{l}\text { Randomized } \\
\text { design }\end{array}$ & $\begin{array}{l}\text { Patients whose first diagnosis } \\
\text { was chronic sinusitis and who } \\
\text { were treated with endoscopic } \\
\text { surgery }\end{array}$ & $\begin{array}{l}\text { Clinical } \\
\text { pathway }\end{array}$ & $\begin{array}{l}\text { Length of stay, length of delay } \\
\text { before operation, total hospital- } \\
\text { ization expenses, patients' } \\
\text { knowledge of health, patient satis- } \\
\text { faction }\end{array}$ & Yes \\
\hline $\begin{array}{l}\text { Shi } \\
\text { [18], } 2014\end{array}$ & Random process & $\begin{array}{l}\text { Chronic sinusitis treated with } \\
\text { endoscopic surgery }\end{array}$ & $\begin{array}{l}\text { Clinical } \\
\text { pathway }\end{array}$ & $\begin{array}{l}\text { Length of stay, total hospitalization } \\
\text { expenses, patients' knowledge of } \\
\text { health, patient satisfaction }\end{array}$ & - \\
\hline $\begin{array}{l}\text { Wang } \\
{[19], 2007}\end{array}$ & $\begin{array}{l}\text { Random process } \\
\text { by date }\end{array}$ & $\begin{array}{l}\text { Chronic sinusitis of } \\
\text { perioperation }\end{array}$ & $\begin{array}{l}\text { Clinical } \\
\text { pathway }\end{array}$ & $\begin{array}{l}\text { Length of stay, length of delay } \\
\text { before operation, total } \\
\text { hospitalization expenses, patients' } \\
\text { knowledge of health, patient satis- } \\
\text { faction }\end{array}$ & - \\
\hline $\begin{array}{l}\text { Wu } \\
{[20], 2014}\end{array}$ & Random process & $\begin{array}{l}\text { Chronic sinusitis of } \\
\text { perioperation }\end{array}$ & $\begin{array}{l}\text { Clinical } \\
\text { pathway }\end{array}$ & $\begin{array}{l}\text { Length of stay, total hospitalization } \\
\text { expenses, patients' knowledge of } \\
\text { health, patient satisfaction }\end{array}$ & - \\
\hline $\begin{array}{l}\text { Xia } \\
{[21], 2007}\end{array}$ & $\begin{array}{l}\text { Random process } \\
\text { by date }\end{array}$ & $\begin{array}{l}\text { Chronic sinusitis treated } \\
\text { with endoscopic surgery }\end{array}$ & $\begin{array}{l}\text { Clinical } \\
\text { pathway }\end{array}$ & $\begin{array}{l}\text { Length of stay, total hospitalization } \\
\text { expenses, patient satisfaction, }\end{array}$ & Yes \\
\hline $\begin{array}{l}\text { Yao } \\
{[22], 2016}\end{array}$ & $\begin{array}{l}\text { Random process } \\
\text { by date }\end{array}$ & $\begin{array}{l}\text { Chronic sinusitis treated } \\
\text { with endoscopic surgery }\end{array}$ & $\begin{array}{l}\text { Clinical nursing } \\
\text { pathway }\end{array}$ & $\begin{array}{l}\text { Length of stay, total hospitalization } \\
\text { expenses, patients' knowledge of } \\
\text { health, patient satisfaction, quality } \\
\text { of life }\end{array}$ & Yes \\
\hline $\begin{array}{l}\text { Zhu } \\
{[23], 2017}\end{array}$ & Random process & $\begin{array}{l}\text { Chronic sinusitis treated } \\
\text { with endoscopic surgery }\end{array}$ & $\begin{array}{l}\text { Clinical nursing } \\
\text { pathway }\end{array}$ & $\begin{array}{l}\text { Length of stay, patients' knowledge } \\
\text { of health, patient satisfaction, } \\
\text { nursing compliance rate }\end{array}$ & Yes \\
\hline $\begin{array}{l}\text { Zuo } \\
{[24], 2008}\end{array}$ & $\begin{array}{l}\text { Random number } \\
\text { table }\end{array}$ & $\begin{array}{l}\text { Chronic sinusitis treated } \\
\text { with endoscopic surgery }\end{array}$ & $\begin{array}{l}\text { Clinical nursing } \\
\text { pathway }\end{array}$ & $\begin{array}{l}\text { Length of stay, total hospitalization } \\
\text { expenses, patients' knowledge of } \\
\text { health, patient satisfaction }\end{array}$ & Yes \\
\hline
\end{tabular}


Yong-Mei et al.: Clinical Pathway: Meta-Analysis

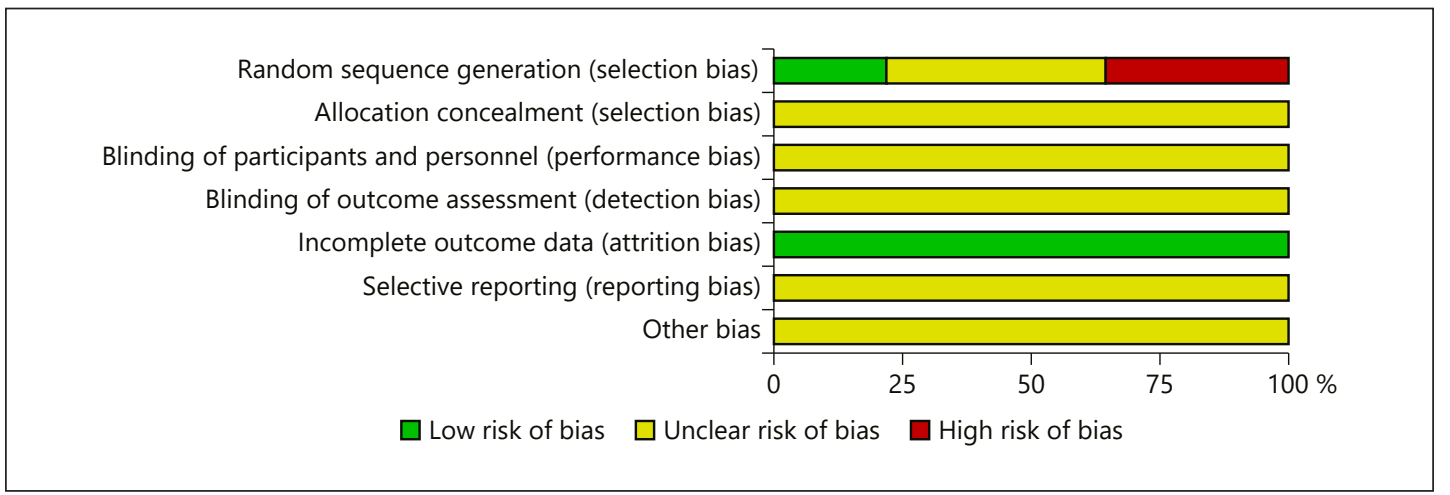

Fig. 2. Risk of bias graph: review authors' judgements about each risk of bias item presented as percentages across all included studies.

geneity among the studies when $I^{2}=75 \%$. The fixed effects model was used for analysis if $p>0.1$ and $I^{2}<$ $50 \%$. Statistical heterogeneity is suggested if $p \leq 0.1$ or $I^{2}=50 \%$. We should analyze the sources of heterogeneity and determine whether a random effects model can be used for analysis. If there is significant clinical heterogeneity between studies, descriptive analysis should be made [9].

Continuous variables were analyzed using the mean difference (MD) for statistics. Risk ratio (RR) was used for statistical analysis. All the results are expressed with 95\% confidence intervals (CIs).

\section{Results}

\section{Selection of Studies}

According to the formulated retrieval strategy, 1,834 articles were preliminarily retrieved. The results were imported into EndNote X7, and 1,472 articles were retrieved by software and manual search; 1,398 unrelated articles were excluded based on topics and abstracts. The remaining 74 articles were collected and carefully read to determine whether they met the exclusion criteria. Finally, we included 14 RCTs (Fig. 1).

According to the Cochrane Collaboration Network Self-Working Manual 5.0.2 Result Reporting Requirements [10]. We present systematically and clearly the research and results of the 14 included documents (Table 2). There were 927 samples in the experimental group and 955 samples in the control group.

\section{Study Characteristics}

Characteristics of Inclusion Studies

The description of the included studies is summarized in Table 2. All 14 references mentioned randomness. Eight studies reported specific methods of sample generation. Five of them were conveniently sampled at the stage of passage and designed according to the sample population generated by the date of hospitalization. Only 2 studies used the random number table method, and another produced a random sequence through the number of hospitalizations.

Risk of Bias of the Included Studies

Figures 2 and 3 show us the risk of bias from our 14 included studies. Our judgements about each risk of bias item are presented as percentages based on all included studies (Fig. 2). Each risk of bias item for every included study is shown in Figure 3. Because of the particu- 


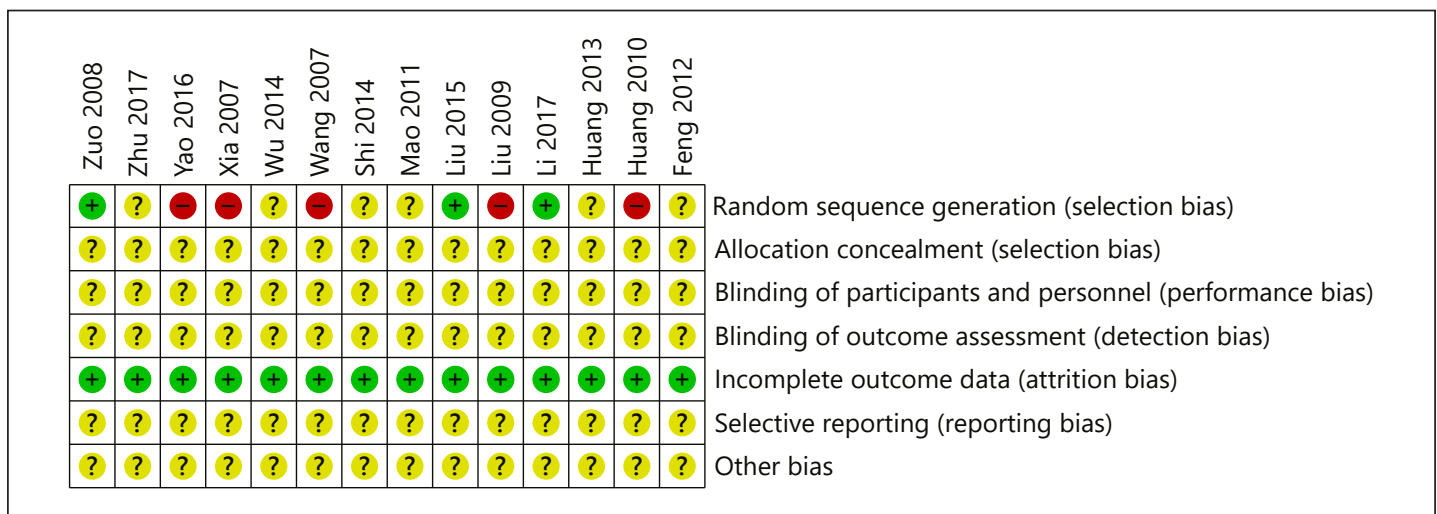

Fig. 3. Risk of bias summary: review authors' judgements about each risk of bias item for each included study.

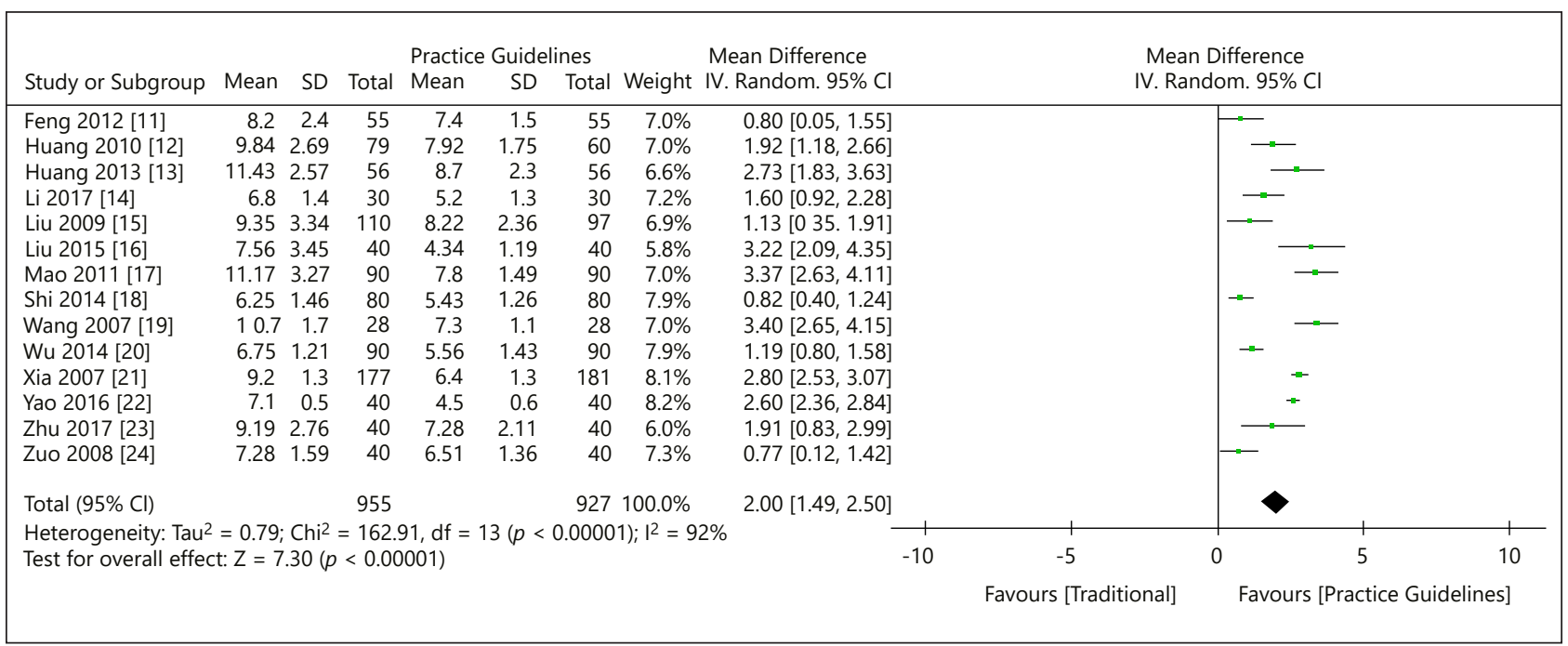

Fig. 4. Forest plot of comparison: different average number of hospitalization days between the traditional pathway and the clinical pathway [11-24].

larity of the interventions for surgery, no blindness method was reported in the included studies. Selective outcome reports and other bias were not clear.

The 14 articles included in this study compared the average number of hospitalization days between the clinical pathway group and the nonclinical pathway group. A total of 955 patients were treated by the traditional route. The number of patients undergoing clinical pathway was 927 . The results showed that the heterogeneity among the studies was high $(p$ $<0.00001, I^{2}=92 \%$ ). Meta-regression analysis may be the cause of heterogeneity, but no heterogeneity caused by regression factors was found. The results showed that there were significant differences between the clinical pathway group and the nonclinical pathway group in the number of hospitalization days per capita (MD $=-2.00,95 \%$ CI: $-2.50,-1.49$ ) (Fig. 4). The length of stay in the clinical pathway group was significantly lower than that in the nonclinical pathway group.

Ten of the 14 articles included in our study compared the hospitalization cost of patients between the clinical pathway group and the nonclinical pathway group. A total of 764 patients were treated with traditional pathway and 736 patients were treated with clinical pathway. 


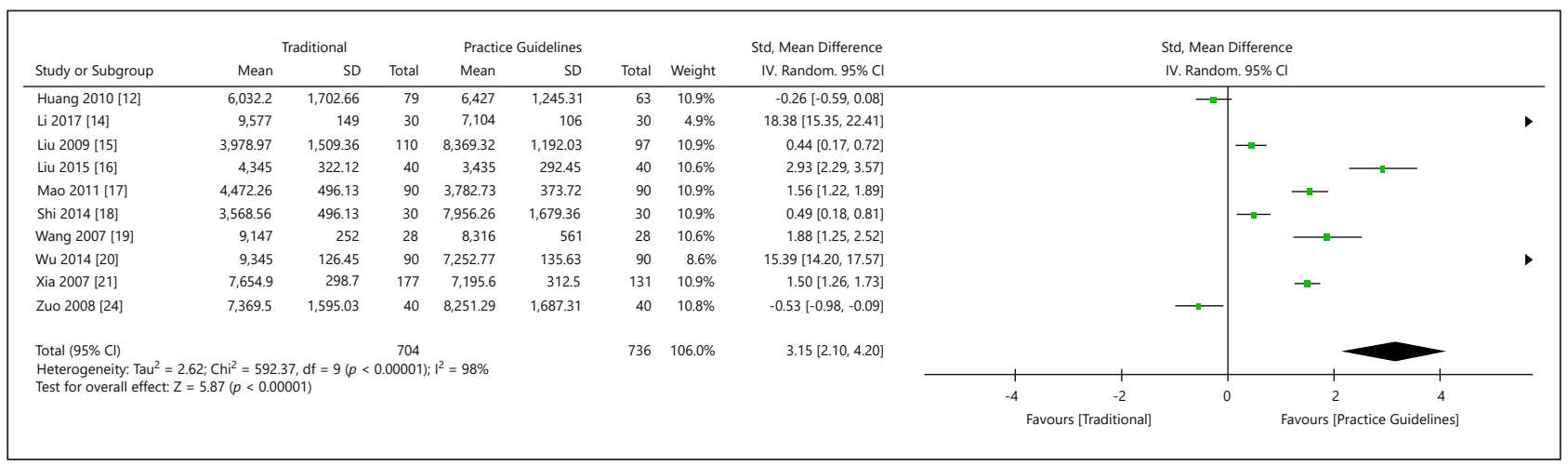

Fig. 5. Forest plot of comparison: different hospitalization cost of patients between the traditional pathway and the clinical pathway $[12,14-21,24]$.

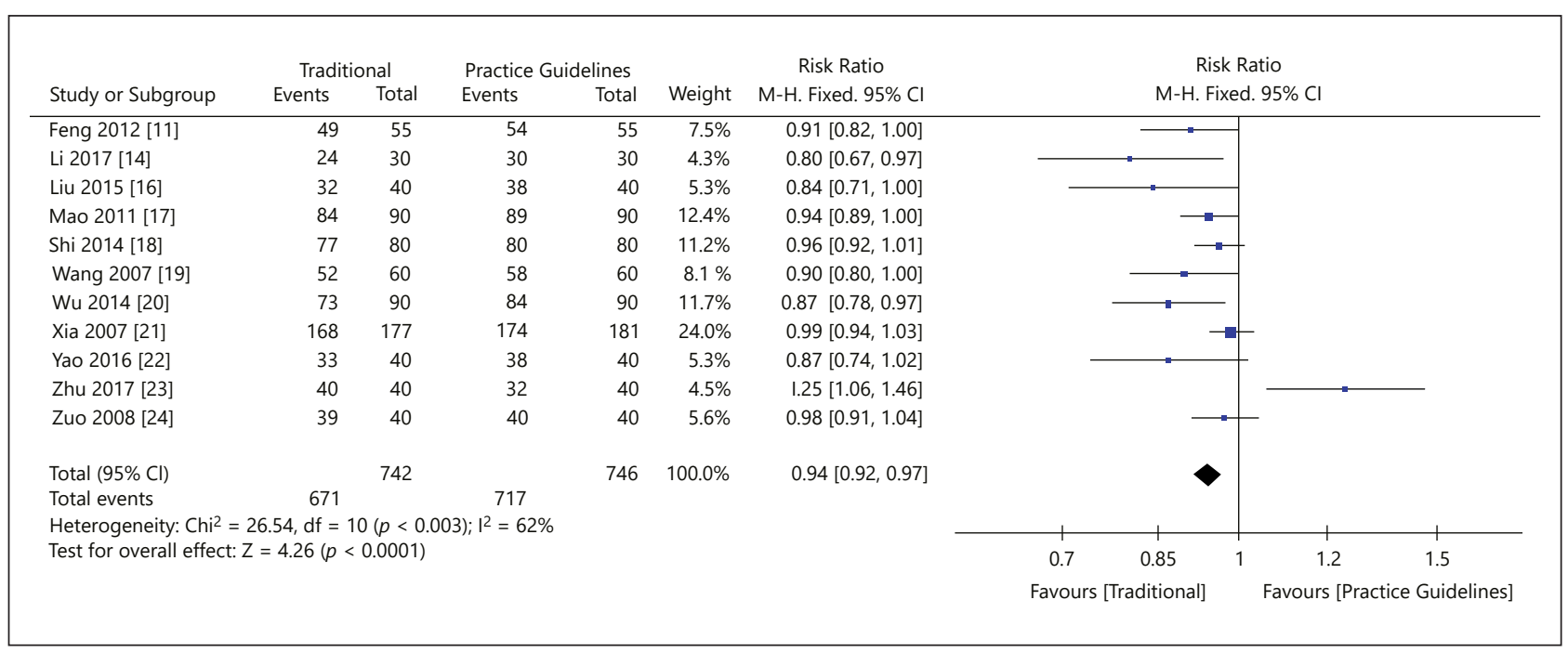

Fig. 6. Forest plot of comparison: different patients' knowledge of health between the traditional pathway and the clinical pathway $[11,14,16-24]$.

The results showed that the heterogeneity among the studies was high $\left(p<0.00001, I^{2}=\right.$ 98\%). Meta-regression analysis may be the cause of heterogeneity, but no heterogeneity caused by regression factors was found. The results showed that there were significant differences between the clinical pathway group and the nonclinical pathway group in per capita hospitalization costs (SMD $=-3.15,95 \% \mathrm{CI}:-4.20,-2.10$ ) (Fig. 5). The hospitalization cost of the clinical pathway group was significantly lower than that of the nonclinical pathway group.

Eleven articles were included in the meta-analysis of patients' knowledge of health in this study. In total, 742 patients were treated with traditional pathway and 746 patients were treated with clinical pathway. In this analysis, the $\chi^{2}$ value is $26.54, p=0.003(<0.05)$, and $I^{2}=62 \%$, indicating obvious heterogeneity. Because the data processed were binary variables, a random effects model was adopted to calculate the combined effect RR value. The value is 1.06 (95\% CI:1.03, 1.09). It can be considered that the combined effect $R R$ is not equal to 1 . That is to say, "patients who implement clinical pathway and traditional pathway have different mastery of health knowledge, there are statistical differences." It can be seen that patients in the clinical pathway group have better mastery of health knowledge (Fig. 6). 
Yong-Mei et al.: Clinical Pathway: Meta-Analysis

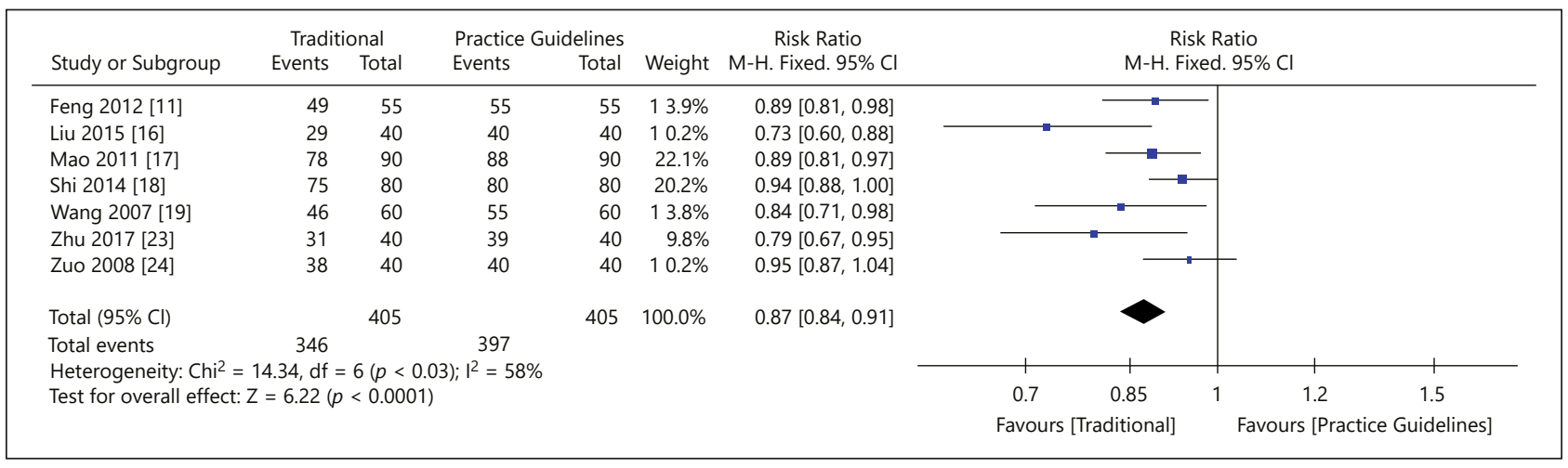

Fig. 7. Forest plot of comparison: different patient satisfaction between the traditional pathway and the clinical pathway [11, 16-19, 23, 24].

Seven papers were included in the meta-analysis of patient satisfaction. Because Shi et al. [18] divided patient satisfaction into four grades, while the rest of the studies had only two grades, our study combined the results of the study into two categories. The number of patients implementing the clinical pathway and the traditional pathway are both 405 . In this analysis, the $\chi^{2}$ value is $14.34, p=0.03(<0.05)$ and $I^{2}=58 \%$, indicating moderate heterogeneity in the study. Because the data processed were binary variables, a random effects model was adopted to calculate the combined effect RR value. The value is 1.15 (95\% CI: 1.10,1.20). It can be considered that the combined effect RR is not equal to 1 . That is to say, "patients' satisfaction with the implementation of clinical pathway is different from that of traditional pathway, and there are statistical differences." It can be seen that patients in the clinical pathway group have higher satisfaction (Fig. 7).

\section{Discussion}

\section{Summary of Results}

This systematic review and meta-analysis of RCTs for operative outcomes demonstrated that compared with the traditional pathway, sinus diameter surgery using clinical pathway can effectively shorten the average number of hospitalization days, reduce the hospitalization costs of patients, improve the level of patients' knowledge of health, and increase patient satisfaction.

These results were based on 14 studies, all of which were RCTs, which were used to study the differences of outcome indicators between the clinical pathway group and the traditional pathway group in patients with chronic sinusitis undergoing endoscopic sinus surgery. All 14 studies mentioned the comparison of the average number of hospitalization days, 10 studies mentioned the comparison of hospitalization costs of patients, 11 studies mentioned the comparison of patients' knowledge of health, and 7 studies mentioned patient satisfaction.

\section{Clinical Implications of the Review}

Chronic sinusitis is a chronic suppurative inflammation of the sinuses, which seriously affects the quality of life of patients. In severe cases, it can cause a series of diseases of the head and neck of otorhinolaryngology. In this study, through a systematic review of the effect analysis of endoscopic sinus surgery through clinical pathway, the current situation of this research direction in China is presented to some extent. 
As a disease with a high recurrence rate, chronic sinusitis is difficult to cure by traditional medicine. At present, endoscopic sinus surgery is the preferred surgical treatment. The purpose of clinical pathway is to control the cost and time of treatment within a reasonable range, improve the prognosis of patients, and improve the efficiency of medical resource utilization. Whether endoscopic sinus surgery with clinical pathway is effective or not is very important for patients and the development of rhinology. This study focused on four common research indicators: the average number of hospitalization days, the hospitalization costs of patients, patients' knowledge of health, and patient satisfaction. The indicators were used to evaluate the effect of clinical pathway in chronic sinusitis and to provide a scientific basis for endoscopic sinus surgery in the treatment of chronic sinusitis.

\section{Comparison with Other Studies}

In 2007, Carlsen et al. [25] indicated that clinical practice guidelines have become a common tool for promoting the quality and equity of services and controlling costs in their study: a meta-synthesis of GPs' attitudes to clinical practice guidelines. However, their impact on practice is highly variable, so it is necessary to review and synthesize their findings systematically. Rouse et al. [26], in their meta-analysis on glaucoma treatment in 2016, proposed that meta-analyses compare multiple treatment options for the same condition and may be useful for developing clinical practice guidelines. Therefore, our study has a certain value.

At present, there are few research articles on meta-analysis of the clinical pathway of sinus diameter surgery for chronic sinusitis at home and abroad. Neuman et al. [27] included 22 studies in the meta-analysis of clinical pathway effect evaluation of knee arthroplasty in 2009 , in which 6,316 patients were analyzed. The results showed that the incidence of postoperative complications in the clinical pathway group was significantly lower than that in the traditional pathway group, and the pathway group was treated. Clinical pathway takes a short time and costs less. This study provides a good reference for the credibility of the indicators.

\section{Limitations of the Review}

Limitations of our systematic review include potential biases in the review process regarding the eligibility criteria and data analyses. Generally speaking, the quality of the research included in this study is not very different, but there are few high-quality studies, and all of them are Chinese literature. This result may be caused by the requirement of the research object for Chinese people. However, there are different clinical pathways applied by different researchers, which increase the heterogeneity among the included studies. All 14 articles included in this study mentioned randomness, but only 3 studies provided a complete and correct way of generating random sequences. Possibly because of the particularity of surgical interventions, no concealed allocation scheme has been reported in the included studies, which may result in selection bias and implementation bias. There is no blindness in the study report, which may lead to interpretation bias in this study.

There are also some limitations in the process of analysis. Firstly, our study just considers the summary cost of hospitalization, not all kinds of expense. Secondly, the biggest limitation of this study is that subgroup analysis could not be carried out. In addition to the four indicators analyzed in this study, only 2 of the 14 studies involved patient waiting days, different kinds of cost, patient compliance, and clinical prognostic outcome indicators. This may be because the indicators in this study can most directly reflect the efficiency of hospital operation. It shows that the current medical reform is still aimed at saving time and expenses. At the same time, health education is emphasized, and patients are guided to improve their own health knowledge reserve. Only 8 of the studies were followed up. This reflects that the importance of relevant research on patient compliance and clinical follow-up needs to be improved. 
Yong-Mei et al.: Clinical Pathway: Meta-Analysis

Six studies included fewer than 100 patients, indicating that the sample size of RCTs for clinical pathways of endoscopic sinus surgery in China still needs to be improved.

With the advancement of medical reform in China, the indicators used to evaluate clinical effects have been divided more carefully. Future systematic reviews and meta-analyses can be further tracked based on changes in RCTs. Suggestions for future research are that RCTs (1) elaborate on the randomized method of the trial and (2) try to implement the blind method in diagnosis. The test should describe in detail the characteristics of the object of study, the method of the test, the quality control, and the division of the measurement indexes of the test. The original data should be reported in the literature. The prospective study method was adopted as far as possible.

\section{Conclusions}

Our systematic review and meta-analysis supports the use of clinical pathway in patients with endoscopic sinus surgery in China. Based on current existing evidence it statistically reduces the average number of hospitalization days, reduces the hospitalization costs of patients, improves the patients' knowledge of health, improves patient satisfaction, and significantly improves the quality of endoscopic sinus surgery.

\section{Disclosure Statement}

The authors declare no conflicts of interest.

\section{Funding Sources}

This study received funding from the Beijing Municipal Administration of Hospitals Talent Development Program "Mission" Talent (SML20150201) and the Major Counselling Research Project "Chinese Health Service Industry Development Strategy Research", Department of Pharmacy, Chinese Academy of Engineering (2015-ZD-06).

\section{Author Contributions}

H.D.-M.: conception, planning, initial draft, and writing the paper; B.Y.-M.: literature search, data extraction, analyzing data, conception of project, writing the paper, and editing the draft. W.D.-B., M.Q.-Z., and P.Y.-D.: data analysis, initial draft, and writing the paper.

\section{References}

1 Raviv JR, Kern RC. Chronic rhinosinusitis and olfactory dysfunction. Adv Otorhinolaryngol. 2006;63:108-24.

2 Benninger MS, Ferguson BJ, Hadley JA, Hamilos DL, Jacobs M, Kennedy DW, et al. Adult chronic rhinosinusitis: definitions, diagnosis, epidemiology, and pathophysiology. Otolaryngol Head Neck Surg. 2003 Sep;129(3 Suppl):S1-32.

3 Rudmik L, Soler ZM, Orlandi RR, Stewart MG, Bhattacharyya N, Kennedy DW, et al. Early postoperative care following endoscopic sinus surgery: an evidence-based review with recommendations. Int Forum Allergy Rhinol. 2011 Nov-Dec;1(6):417-30. https://doi.org/10.1002/alr.20072.

4 Kitchiner DJ, Bundred PE. Clinical pathways. Med J Aust. 1999 Jan;170(2):54-5.

5 Zhu J, Li W, Chen L. Doctors in China: improving quality through modernisation of residency education. Lancet. 2016 Oct;388(10054):1922-9. 
Yong-Mei et al.: Clinical Pathway: Meta-Analysis

6 Zeng X, Zhang Y, Kwong JS, Zhang C, Li S, Sun F, et al. The methodological quality assessment tools for preclinical and clinical studies, systematic review and meta-analysis, and clinical practice guideline: a systematic review. J Evid Based Med. 2015 Feb;8(1):2-10.

7 Lefebvre C, Manheimer E, Glanville J. Searching for Studies. In: Higgins JPT, Green S, editors. Cochrane Handbook for Systematic Reviews of Interventions: Cochrane Book Series. The Cochrane Collaboration; 2008. p. 95-150.

8 Rana SS, Kharbanda OP. Letter to editor on "Efficiency of bimaxillary advancement surgery in increasing the volume of the upper airways: a systematic review of observational studies and meta-analysis." Eur Arch Otorhinolaryngol. 2017 Jan;274(1):585.

9 Higgins JPT, Altman DG. Assessing risk of bias in included studies. In: Higgins JPT, Green S, editors. Cochrane handbook for systematic reviews of interventions: Cochrane Book Series. The Cochrane Collaboration; 2008. p. 187-241.

10 Richer L, Billinghurst L, Linsdell MA, Russell K, Vandermeer B, Crumley ET, et al. Drugs for the acute treatment of migraine in children and adolescents. Cochrane Database Syst Rev. 2016 Apr;4(4):CD005220.

11 Feng Q, Pan M. Application of clinical pathway in chronic endoscopic sinusitis surgery. Journal of Qiqihar University of Medicine. 2012;33(5):666-7. Available from: https://doi.org/10.3969/j.issn.10021256.2012.05.070. Chinese.

12 Huang J, FU J, Chen XX, Zhu YM. Assessment on clinical pathway of chronic sinusitis in the perioperative period. Gansu Journal of Traditional Chinese Medicine. 2010 Aug;23(8):18-9. Available from: https://doi. org/10.3969/j.issn.1004-6852.2010.08.010. Chinese.

13 Huang Y. Application of clinical pathway in patients with chronic sinusitis. Mod Diagn Treat. 2013 Dec;24(20): 4803-4. DOI: 1001-8174(2013)20-4803-02. Chinese.

14 Li W, Zhu X. Application of clinical pathway in endoscopic sinus surgery for chronic sinusitis. China Medicine \& Pharmacy. 2017 Nov;7(22):113-6. Available from: https://doi.org/10.3969/j.issn.2095-0616.2017.22.035. Chinese.

15 Liu D. Study on establishment and evaluation of clinical pathway for chronic sinusitis [Doctoral dissertation]. Guangzhou University of Chinese Medicine; 2009. Chinese.

16 Liu Y. Application value of clinical pathway in chronic rhinosinusitis. World Clin Med. 2015 Apr;9(4):228-9. Chinese.

17 Mao S. Application research of clinical pathway in operative patients with chronic sinusitis. Xiandai Yiyao Weisheng. 2011;20(15):2289-90. Chinese.

18 Shi Z, et al. Application of clinical pathway in chronic sinusitis healthy education during perioperative period. Journal of Anhui Health Vocational \& Technical College. 2014;6:75-6. Chinese.

19 Wang J, Su G, Lai S. Application of clinical nursing path in otorhinolaryngologic patients undergoing selective operation. Family Nurse. 2007 Feb;5(2):1-2. Chinese.

20 Wu Y, Liao R. Application of clinical nursing path in otorhinolaryngologic patients undergoing selective operation. Medical Information. 2014 Feb;11:286. Available from: https://doi.org/10.3969/j.issn.1006-1959. 2014.33.434. Chinese.

21 Xia J, Li Y, Chen Q. Evaluation of the benefit of implementing clinical pathway to ESS. Modern Hospital. 2007 Apr;7(4):104-6. Chinese.

22 Yao E, Yang C, Zhao M, Zhou Y. Establishment and evaluation of perioperative clinical nursing pathway for chronic rhinosinusitis patients undergoing endoscopic sinus surgery. Journal of Taishan Medical Colledge. 2016 Nov;37(11):1289-90. Available from: https://doi.org/10.3969/j.issn.1004-7115.2016.11.035. Chinese.

23 Zhu J, Huang F, Huang J. Analysis of clinical nursing pathways in endoscopic sinus surgery for chronic sinusitis. Chinese \& Foreign Medical Research. 2017 Nov;15(31):95-96. DOI: CNKI:SUN:YJZY.0.2017-31-047. Chinese.

24 Zuo D. Application of clinical nursing path in endoscopic surgery of chronic sinusitis. China Academic Journals [Electronic]. 2008; 24(12):2172-3. Available from: https://doi.org/10.3969/j.issn.1006-5725.2008.12.080. Chinese.

25 Carlsen B, Glenton C, Pope C. Thou shalt versus thou shalt not: a meta-synthesis of GPs' attitudes to clinical practice guidelines. Br J Gen Pract. 2007 Dec;57(545):971-8.

26 Rouse B, Cipriani A, Shi Q, Coleman AL, Dickersin K, Li T. Network meta-analysis for clinical practice guidelines: a case study on first-line medical therapies for primary open-angle glaucoma. Ann Intern Med. 2016 May; 164(10):674-82.

27 Neuman MD, Archan S, Karlawish JH, Schwartz JS, Fleisher LA. The relationship between short-term mortality and quality of care for hip fracture: a meta-analysis of clinical pathways for hip fracture. J Am Geriatr Soc. 2009 Nov;57(11):2046-54. 